www.jmscr.igmpublication.org

Impact Factor 5.244

Index Copernicus Value: 83.27

ISSN (e)-2347-176x ISSN (p) 2455-0450

crossref DOI: _https://dx.doi.org/10.18535/jmscr/v4i10.93

\author{
Journal Of Medical Science And Clinical Research \\ IGM Publication \\ An official Publication of IGM Publication
}

\title{
Reoperative Thyroid Surgery - Our Experience
}

Authors

\author{
Dr S. Zahir Hussain, Dr M.P. Kumaran
}

\begin{abstract}
Aim: Reoperative thyroid surgery is not an uncommon operation. It is associated with a higher rate of complication; we prospectively analysed 53 patients who had reoperative surgery for recurrent goiter.

Method: 60 patients had a thyroid reoperation for recurrentmultinodular goiter (48 patients), recurrent thyrotoxicosis (9) or suspected malignancy (3); bilateral lobectomy (36 patients), unilateral lobectomy (24 patients)

Results: After unilateral surgery we had only 3 patients of transienthypoparathyroidism (\%) and 1 trasient recurrent laryngeal nerve palsy (\%),after bilateral surgery wehad 10patients of transient hypoparathyr-oidism (\%), 1 of definitive (\%), 6 of transient recurrent laryngeal nerve palsy (\%), and 1 of postoperative bleeding (\%). Conclusions: Reoperative thyroid surgery is a technical challengewith a high incidence of complications. Scarring of the tissues together with distortion of the landmarks make reoperative surgery difficult. A higher risk of complications is described when previous surgery has been performed on both sides. Total thyroidectomy should be considered the procedure of choice for benign multi nodulargoiter eliminating the potential of a reoperation. Subtotal thyroidectomy should therefore no longer be recommended in the management of multinodulargoitre. Whenever necessary, reoperative thyroidectomy may be performed safely with little morbidityin experienced hands.
\end{abstract}

\section{Introduction}

The extent of surgery for benign thyroid diseases has from subtotal thyroidectomy to total thyroidectomy and it is still a matter of debate. Subtotal thyroidectomy has been the standard procedure for many years. It was thought to be a safe procedure. Risk of recurrent goiter after subtotal thyroidectomy, which ranges from 3\% to $43 \%{ }^{(1-3)}$. Suppression of TSH L-thyroxin therapy can be used to prevent the recurrence and is useful only in $30 \%$ of patients ${ }^{(1,4-9)}$. Reoperative thyroid surgery is indicated in case of recurrent unilateral or multi nodular goiter, when it is associated with compression or in case of suspected malignancy, and in recurrent thyrotoxicosis ${ }^{(7,10)}$.
The scar tissue from previous surgery make recurrent laryngeal nerve and vascular pedicle of the parathyroid vulnerable for injury ${ }^{(11)}$. We reviewed our patients on whom thyroid surgery was performed.

\section{Patients and Methods}

From September 2011 to December 2015.60 patients $(\%)$ had at hyroid reoperation which is $4 \%$ of thyroid surgeries for recurrent multi nodular goiter (48patients), recurrent thyrotoxicosis (9 patients) or suspected malignancy (3 patients). There were 52 women and 8 men. Two of the initial operations in these patients were performed by our team in other centers. The 
median interval between the prior operation and the reoperation was 273 months (range 1 month30 years). Preoperative thyroid ultrasound and indirect laryngoscopy was performed on all patients ${ }^{(12,13)}$. Secondary thyroidectomy was performed using a standard operative technique. Dissection was begun laterally by mobilizing sternocleido-mastoid muscles and dividing infrahyoid muscles to avoid fibrous tissue around the thyroid remnant when the lobe had been partially removed during previous surgery. If the lobe to be resected had not been disturbed at prior operation, we proceeded through infra-hyoid muscles to avoid fibrosis around the anterior face of the trachea. The first step was ligation of the superior thyroid vessels and special attention being paid to the superior parathyroid gland and the external branch of the superior laryngeal nerve. Then the recurrent laryngeal nerve was identified in the lower part of the neck and traced very carefully along its cervicalcourse. Intra-thoracic goiters extending into the superior mediastinum were removed by progressive traction through the collar incision. Amedian sternotomy was necessary in one patient with a large recur- rentmultinodular goiter with substernal extension. The inferior parathyroid gland was preserved with its vessels when it was located far from thyroid lobe. Any parathyroid gland that could not be salvaged because of its anatomic location was minced and placed in a sternocleidomastoid muscle. If the course of reoperation was uneventful, the patient was discharged from the hospital on postoperative day 2. We did not do routine laryngoscopy postoperatively in this series. Indirect laryngescopy was repeated after reoperation in patients with dyspnea, hoarseness, or loss of voice quality. Serum calcium and phosphorus levels were measured daily while patients were hospitalized and weekly postoperatively until normalization. Bilateral completion thyroidectomy was performed in 68 cases, in 3 cases associated with lymphadenectomy, in 3 associated with parathyroiddectomy, with lobectomy in 36 cases, removal of a mediastinal recurrence in 1 case and removal of a pyramidal remnant in 1 case.

\section{Results}

Histological examination revealed papillary cancer in 19 patients (3 micro carcinomas), follicular cancer in 1and medullary cancer in 1 . In 11 cases malignant neoplasm was unsuspected, in 10 cases preoperative suspect of cancer was confirmed.

Mean operative time was 140 minutes (range: 60260). All patients were submitted to a minimum follow-up of 6 months. Temporary hypoparathyroidism occurred in 41 patients $(38.67 \%)$ and definitive hypoparathyroidism in7 patients $(6.6 \%)$. In patients submitted to primary thyroidectomy the incidence was $23.2 \% \quad(\mathrm{p}=0.0002)$ and $2.4 \%$ $(\mathrm{p}=0.0171)$ respectively (Table 1$)$. Transient recurrent laryngeal nerve palsy occurred in5 cases $(4.71 \%)$ and permanent nerve palsy in $1(0.94 \%)$. In primary thyroidectomies incidence was $0.9 \%$ $(\mathrm{p}=0.0009)$ and $0.3 \% \quad(\mathrm{p}=0.7591)$ respectively (Table 1).In 3 cases $(2.83 \%)$ surgical revision of haemostasis was necessary for postoperative haemorrhage. In all cases bleeding happened in the first 6 hours and we had intra operative findings of diffuse haemorrhage without evidence of a major vessel bleeding. In primary thyroidectomies incidence was $1.3 \%(\mathrm{p}=0.3613$ ) (Table 1). After one side surgery we had 13 cases of transienthypoparathyroidism (34.21\%), 2 cases of definitive hypoparathyroidism (5.26\%), 1 transient recurrent laryngeal nerve palsy $(2.63 \%)$, no definitive recurrent laryngeal nerve palsy and no bleedings (Table 2). After bilateral surgery we had 29 cases of transienthypoparathyroidism $(42.64 \%), 5$ cases of definitive hypoparathyroidism $(7.35 \%), 4$ cases of transient recurrent laryngeal nerve palsy $(5.88 \%), 1$ case of definitive recurrent laryngeal nerve palsy $(1.47 \%)$ and 3 cases of postoperative bleeding $(4.41 \%)$ (Table 2 ). Differences werenot statistically significant. 


\section{Discussion and Conclusions}

Reoperative thyroid surgery is a technical challenge with a high incidence of complications (11). Scarring, edema and friability of the tissues together with distortion of the landmarks make reoperative surgery hazardous ${ }^{(15)}$. The complications are mainly related to the extent of the recurrent disease, the proximity of disease to the recurrent laryngeal nerve and the indications for which reoperative surgery is performed, along with scarring and fibrosis ${ }^{(11)}$. The risk varies according to the initial surgical resection: unilateral lobectomy versus bilateral subtotal lobectomy ${ }^{(16)}$. A higher risk of complications is described when previous surgery has been performed on both sides ${ }^{(10)}$. The risk of complications increased with the number of reoperations ${ }^{(7)}$. In particular, a higher risk of hematomas in reoperative surgery is reported in literature ${ }^{(17) .}$ Our experience shows a higher risk of complications for bilateral surgery, particularly for postoperative bleedings, but differences were not statistically significant. One of the most feared complications of repeated thyroid surgery is the recurrent laryngeal nerve injury ${ }^{(18)}$. The risk of a recurrent laryngeal nerve palsy is said to be eight times higher after operation for relapses than after the primary operation ${ }^{(19)}$. The incidence of temporary and permanent palsy of recurrent laryngeal nerve may be as high as $20 \%$ in recurrent goiters ${ }^{(15)}$. Reoperative thyroid surgery had more frequent recurrent laryngeal nerve injuries, both temporary $(0-22 \%)$ and permanent $(0-13 \%)^{(7,20)}$. Hyperthyroidism and not exposing the nerve during operation were predisposing factors ${ }^{(10,19)}$. In our experience transient recurrent laryngeal nerve palsy was five times higher than for primary operations and difference was highly significant. Permanent palsy was also higher for secondary surgery but the difference was not statistically significant.

Another feared complication of repeated thyroid surgery is permanent hypoparathyroidism which can be a very disabling complication ${ }^{(18)}$. A very high risk of hypoparathyroidism was noticed in literature for reoperative thyroid surgery: it has been reported that the incidence of transient hypoparathyroidism was $0 \%$ to $25 \%$ and of definitive hypoparathyroidism from $0 \%$ to $22 \%$ $(7,8,18,20,21)$. The exact position of parathyroid glandsmay be obscured by scar tissue from the previous operative procedure (18). In our experience the incidence of transient and definitive hypoparathyroidism was very high (38.67\% and 6.6\%) compared with primary thyroidectomies and the difference was statistically significant, particularly for transitory hypoparathyroidism. The mortality after repeat operations is $0.61 \%$, which is three times more than during initial operation ${ }^{(19)}$. We had no mortality in our experience.

In repeat surgery for recurrences the lateral approach is popular as it avoids the infiltration by connective tissue of Kocher's approach (7, 10, 22) and allows identification of the nerves in a previously un-dissected area ${ }^{(23)}$. Rather than reopening the median raphe, the straps are retracted medially and a plane anterior to the sternocleidomastoid muscle is entered ${ }^{(7)}$. The recurrent laryngeal nerve should be always identified, usually in the lower neck, then followed along its cervical course ${ }^{(7,24)}$. However, no significant difference in the rate of palsy between the lateral and medial approach was reported. A tendency for a slightly higher rate of palsy using the lateral approach was reported in one study ${ }^{(7)}$. A possible explanation is that the lateral approach avoids the connective tissue ventrally, but dorsally it cannot be avoided by either approach where the nerve is at risk; moreover, surgeons usually have less experience using the lateral approach and hence the surgical field and anatomymay be less familiar ${ }^{(7)}$. Intraoperative neuromonitoring can be useful in reoperative thyroid surgery especially when the anatomic situation diverges from the normal. In fact, intraoperative neuromonitoring may reduce the morbidity of reoperative thyroid surgery ${ }^{(15)}$. In our opinion intraoperative neuromonitoring may be particularly useful for reoperative thyroid 
surgery, making the detection of the nerve in the scar tissue easier. Unfortunately our experience in neuro monitoring is short and it's not possible to obtain statistically significant results. Finally total thyroidectomy is the most effective operation for preventing recurrence of benign nodular goiters (7). In addition to disease recurrence, numerous studies have demonstrated that a significant proportion of patients who have surgery for multinodular goiter harbour occult malignancy. Removing all thyroid tissue eliminates the risk of developing recurrent disease and thyroid carcinoma in the remnant tissue ${ }^{(3)}$. In our experience histological examination revealed malignancy in 21 patients $(19.81 \%)$; in 11 cases $(10.37 \%)$ malignantneoplasm was unsuspected, in 10 cases preoperative suspect of cancer was confirmed. In medullary cancer molecular genetics techniques such as study of RET mutation can be very useful in the diagnosis and in the management of the operation ${ }^{(25)}$. In conclusion, reoperative thyroid procedures havea higher rate of complications because of scarring and loss of normal tissue planes. For this reason every effort should be made to avoid them by performing definitive initial treatment; thus total thyroidectomy should be considered the procedure of choice for benign multi nodular goiter eliminating the potential of a reoperation. Careful evaluation of the patient's risk factors, physical examination, and the fine needle aspiration cytology is crucial for selecting those could most benefit from the reoperation. Whenever it is necessary, reoperative thyroidectomy may be performed safely with little morbidity in experienced hands.

\section{References}

1. Colak T, Akca T, Kanik A, Yapici D, Aydin S. Total versus sub-total thyroidectomy for the management of benign multinodulargoiter in an endemic region. ANZ J Surg 2004;74:974-8.

2. Gibelin $H$, Sierra M, Mothes D, Ingrand $P$, Levillain $\mathrm{P}$, Jones C,Hadjadj S,
Torremocha F, Marechaud R, Barbier J, KraimpsJL.Risk Factors for Recurrent Nodular Goiter after Thyroidectomy for Benign Disease: Case-control Study of 244 Patients. WorldJ Surg 2004;28:1079-82.

3. Terris DJ, Khichi S, Anderson SK, Seybt MW. Reoperative thyroidectomy for benign thyroid disease. Head Neck 2010;32:285-9.

4. Ambrosi A, Pezzolla A, Barone G, Quaranta G, Errico D, Iacobone M, Ciampolillo A, Triggiani V. Studio clinicodellafunzione residua e dellerecidive in pazientioperati di tiroidectomieparziali per strumanodulareeutiroideo. Ann ItalChir1994;65:543-6.

5. Bellantone R, Lombardi CP, Boscherini M, Raffaelli M, TondoloV, Alesina PF, Corsello SM, Fintini D, Bossola M. Predictive factors for recurrence after thyroid lobectomy for unilateral non-toxic goiter in an endemic area: Results of a multivariate analysis. Surgery 2004; 136:1247-51.

6. Calò PG, Tuveri M, Pisano G, Tatti A, Medas F, Donati M, Nicolosi A. Il gozzorecidivo. Nostra esperienza. ChirItal 2009;61:545-9.

7. Menegaux F, Turpin G, Dahman M, Leenhardt L, ChadarevianR, Aurengo A, Du Pasquier L, Chigot JP. Secondary thyroidectomy in patients with prior thyroid surgery for benign disease:A study of 203 cases. Surgery 1999;125:479-83.

8. Moalem J, Suh I, Duh QY. Treatment and Prevention of Recurrence of Multinodular Goiter: An Evidence-based Review ofthe Literature. World J Surg 2008;32:1301-12.

9. Torre GC, Borgonovo G, Arezzo A, Bruzzone D, Ansaldo GL,Puglisi M, Mattioli FP. Il gozzorecidivato: analisi di 134 interventi. Ann ItalChir 1996;67:35763.

10. Lefevre JH, Tresallet C, Leenhardt L, Jublanc C, Chigot JP, Menegaux F. 
Reoperative surgery for thyroid disease. LangenbecksArch Surg 2007;392:685-91.

11. Shaha AR. Revision Thyroid Surgery Technical Considerations.OtolaryngolClin N Am 2008;41:1169-83.

12. Trimboli P, Condorelli E, Catania A, Sorrenti S. Clinical and ultrasound parameters in the approach to thyroid nodules cytologically classified as indeterminate neoplasm. Diagn Cytopathol 2009;37:7835.

13. Trimboli P, Ulisse S, D'Alò M, Solari F, Fumarola A, RuggieriM, De Antoni E, Catania A, Sorrenti S, Nardi F, D'ArmientoM. Analysis of clinical, ultrasound and colour flow-Doppler characteristics in predicting malignancy in follicular thyroid neoplasms. ClinEndocrinol 2008;69:342-4.

14. D'Ajello F, Cirocchi R, Docimo G, Catania A, Ardito G, Rosato L, Avenia N. Thyroidectomy with ultrasonic dissector: a multicentric experience. G Chir 2010;31:289-92.

15. Johnson S, Goldenberg D. Intraoperative Monitoring of the Recurrent Laryngeal Nerve During Revision Thyroid Surgery. OtolaryngolClin N Am 2008;41:1147-54.

16. Peix JL, Van Box Som P, Olagne E, Mancini F, Bourdeix O. Résultats des réinterventions pour goitres. Ann Chir 1997;51:217-21.

17. Calò PG, Pisano G, Piga G, Medas F, Tatti A, Donati M, Nicolosi A. Postoperative hematoma after thyroid surgery. Incidenceand risk factors in our experience. Ann ItalChir 2010;81:343-7.

18. Chao TC, Jeng LB, Lin JD, Chen MF. Reoperative Thyroid Surgery. World J Surg 1997;21:644-7.

19. Muller PE, Jakoby R, Heinert G, Spelsberg F. Surgery for Recurrent Goitre: Its Complications and their Risk Factors. Eur JSurg 2001;167:816-21.
20. Wilson DB, Staren ED, Prinz RA. Thyroid Reoperations: Indications and Risks. Am Surg 1998;64:674-8.

21. Calò PG, Farris S, Tatti A, Piga G, Malloci A, Nicolosi A. Le urgenze in chirurgiatiroidea. Nostra esperienza. ChirItal 2006;58:323-9.

22. Levine KE, Clark AH, Duh QY, Demeure M, SipersteinAE,Clark OH. Reoperative thyroid surgery. Surgery 1992;111:604-9.

23. Moley JF, Lairmore TC, Doherty GM, Brunt LM, Debenedetti MK. Preservation of the recurrent laryngeal nerves in thyroidand parathyroid reoperations. Surgery 1999;125:673-9.

24. Pironi D, Panarese A, Candioli S, Manigrasso A, La Gioia G, Romani AM, Arcieri S, Mele R, Filippini A. Reinterventi in chirurgiatiroidea: contributocasistico e revisionedellaletteratura. G Chir 2008;29:407-12.

25. Conzo G, Circelli L, Pasquali D, Sinisi A, Sabatino L, AccardoG, Renzullo A, Santini L, Salvatore F, Colantuoni V. Lessons tobe learned from the clinical management of a MEN 2A patientbearing a novel 634/640/700 triple mutation of the RET proto-oncogene. ClinEndocrinol 2012; In Press, doi: 10.1111/j.13652265.2012.04412.x. 